\title{
Research on the Multidimensional Interactive Foreign Language Teaching Model Based on the Network Information Technology
}

\author{
Bo Zhang ${ }^{1, a}$ and Bai Qin ${ }^{1, b}$ \\ ${ }^{1}$ Harbin University of Science and Technology, Harbin Heilongjiang Province, China \\ abo2016@163.com, bqinbai2006@163.com
}

Keywords: Information technology, Foreign language teaching, Teaching mode.

\begin{abstract}
In today's world, science and technology rapidly progress with information technology as the main symbol. The informatization of social life and the globalization of economic activity make foreign language become the important tool of our country opening to the outside world and associate with countries. The cultivation of high-quality talents in the field of foreign language is faced with new challenges. Modern foreign language teaching must keep pace with the times. Multi-level and multi-dimensional interactive efficient foreign language teaching mode which is vertical and horizontal combination including 'layered strategy' and 'training strategy' and so on should be built by making full use of multimedia and network information technology
\end{abstract}

\section{Introduction}

Language teaching depends on class teaching, and four aspects of the problem including the single pace, the only teaching material, lagging feedback and passive learning generally exist in the traditional foreign language classroom teaching. In recent years, there are a lot of fruitful explorations on network information of the teaching and multidimensional problems in foreign language teaching with the curriculum reform as the main line. In terms of the study of teaching mode, three aspects of the problem, including the construction of informationalized classroom and teaching, new teaching strategies and effective teaching, should be focused on. Foreign language classroom should take the student as the center, take effective teaching as the core and be based on the network information technology, and a multi-dimensional interactive teaching mode should be built to inspire and guide the students to synchronize thinking and application [1]. To achieve the teaching goal, firstly, the connotation of effective teaching must be clear. Secondly, the basic features of multimodal network informationization teaching mode must be understood. Thus effective teaching mode could be built by grasping the teaching rule [2].

\section{How network information technology promotes the effective teaching}

The concept of effective teaching originates from the western scientific teaching movement in the early 20th century. It emphasizes on costing at the minimum, while promoting students' progress at the maximum, fulfilling the expected teaching goals and meeting the demand of teaching. It is a new concept in modern teaching, evaluated by the progress and development students required during the teaching process.

Experimental research on effective teaching emphasizes on 'design consciousness' and 'self-examination consciousness', which stresses on starting the teaching design based on the 'teaching concept' [3]. There are three kinds of effective teaching in terms of 'teaching design', constructivism, scientism and the theory of multiple intelligences, respectively. Aiming at developing students' creative ways of thinking and explore ability, constructivism emphasize on students, especially on the students' self exploration, discovery and the construction of the knowledge learned. Teachers should play the role to help to improve these abilities. While, scientism based on the universal laws of cognitive learning. In this theory, a variety of learning outcomes, the scientific way of classification and the micro-teaching design are concentrated. In the theory of multiple intelligences, the nature of intelligence should be diversified, not single. It is a set of abilities rather 
than a single ability, which is the same as its structure that is multivariate. However, different abilities exist in an independent way. As employees with various capacity and applied ability are needed, school education has to promote students' intelligence development in every aspect and has to provide the atmosphere in which students' personalities can well built.

Network teaching is an interactive mode in which teachers interact with students. It is based on resources from paper books, CD software and internet. Emphasizing on students' self-study, it aims to foster students with the following capacities: information retrieval capacity, information storage capacity, multimedia expressing capacity, moral emotion capacity, cooperative learning capacity and independently studying capacity. This is helpful for developing students' creative thinking and enlarging their scope of knowledge. Meanwhile, the new teaching mode also put forward higher requirements to teachers in different aspects, which includes professional knowledge, information literacy and the scope of knowledge. Teachers will experience and learn non conventional ways of thinking from students, a long with the development of their creative thinking. This, in return, helps teachers enlarge their knowledge as well.

Applying theoretical and empirical research in informatization to language teaching, will definitely contribute to improving the present boring and inefficient situation of foreign language teaching.

\section{Multidimensional interactive teaching mode}

Multidimensional interactive teaching mode has great advantages on language study. Then, what is multidimensional interactive teaching mode? The main content of multidimensional interactive teaching mode is shown as Fig.1.

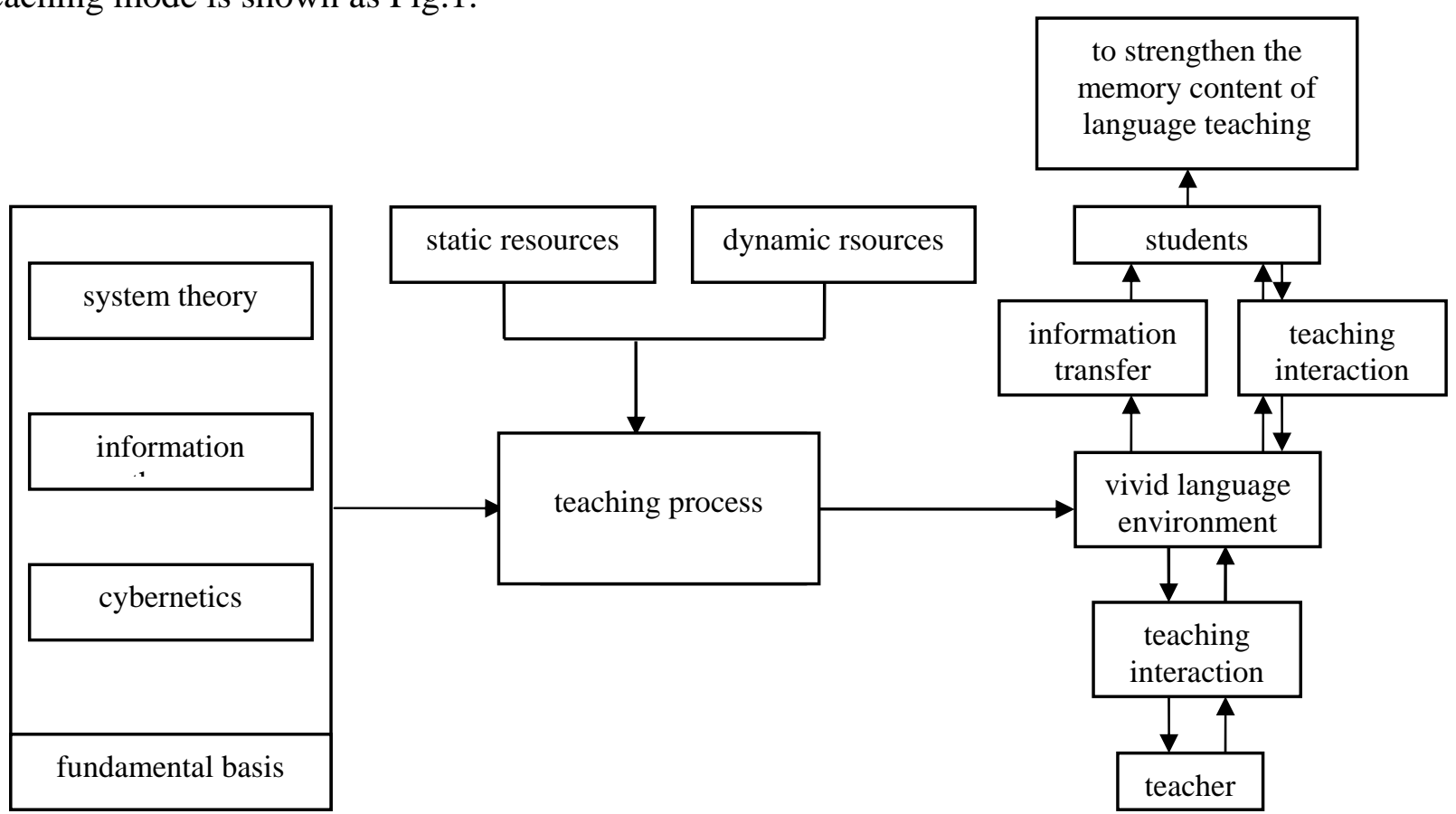

Fig.1 Multidimensional interactive teaching mode

This mode takes system theory, information theory and cybernetics as its fundamental basis as shown in Fig.1. And through adopting static and dynamic resources in the rich media into the target language teaching process, vivid language environment will be constructed, and language information can be transferred to students by using multidimensional ways including seeing, listening, sense and thinking mode, etc. This may cause multi-level association of the students and enhance the memorization of the language teaching content [4]. Moreover, students are not only the information receptors but also information passers. They can also use a variety of media and information to interactive with teacher, and to build the effective interaction evaluation.

For example, in Japanese universities, teachers are concerned to the application of educational psychology, and the 'Seminar' teaching mode is highly regarded. Seminar is a very common way in 
teaching and scholar communication, through which teachers and students discuss one certain problem in an interactive way. Under the instruction of director, students study certain content by autonomous learning from books, journal papers and network information, then summarize the relative materials in a paper report and discuss with others in the group meeting. All the group members, including the director and his students, can tell their own opinion on this topic. The communication among the people with different knowledge structure, and experience brings new cognitive experience to the students. Moreover, regular intercollegiate large workshop, in turn presided by the students of these, increases exchanges and learning between universities, and creates an atmosphere conducive to overcome the subjectivity and bias in the single teacher guidance. This is good for the rapid development in the major to students. therefore, the seminar teaching mode, widely adapted in Japanese universities, its core content is to fully tap the potential of students, to put multi angle, multi-level interaction into practice, thus to deepen understanding on a certain topic and to achieve the best effect of academic exchanges, and to truly achieve 'teaching benefits teachers as well as students learn something' [5]. This mode not only Mobilizes students' learning initiative and cultivates self-learning ability of students, but also improves the students' ability of oral expression and stimulates their participation awareness.

\section{Practice of network information technology and multi-dimensional interactive teaching mode on the foreign language classroom}

Foreign language acquisition is mainly achieved by learning and training. And now, the strategy will be presented as follows aiming at the two links of teaching methods and language training.

Realizing information layered teaching strategy which takes the students as the center, teachers as the leading factor. Informatization is a teaching way of cultivating comprehensive ability. The advantages of informationized education in foreign language teaching are obvious, including Information resources opening, multi-exchange of media and transmission system of multimedia. This characteristic determines that the process of English teaching under the network environment is global, interactive, and has content choice autonomy and personalization, content and form of multimedia. This is in the aim of quality education. The foreign language information-based teaching firstly requires that teachers, teaching material, teaching means should all service for students. The teacher should change the teaching mode of giving the whole of a lesson, and let the students learn to autonomous learning. Secondly, in teaching practice, teachers should overcome the disadvantages that the single mode communication symbols cause the teaching tedious and rigescent. Symbols resources such as language symbols, emoticons, posture symbol, and so on should be optimized to participate in teaching together. And the teacher should make good use of all kinds of teaching resources such as projection, material object, animation and multimedia, and so on to restore the real language communication environment, and mobilize students' learning interest.

And it is not allow ignoring that any class's students have individual differences in the receiving and learning new knowledge. And the satisfaction of individual needs is the basis of the intention to stimulate students to learn, is the important condition to realize effective teaching. The stratification teaching should be promoted by cooperative learning and in-class and after-class tutorial such as foreign language conversation foreign language audio-visual skills. It has not only a direct relationship with the students' basic knowledge level of foreign language but also a close relationship with individual presentation skills and reaction capacity, etc. Therefore, students' differences should be envisaged and respected, layered and hierarchic targeted teaching and coaching should be carried out. And taking the student as the center and teaching students in accordance of their aptitude should be done indeed.

Extending class function and guiding the student to use a variety of information resources and realizing multi-dimensional interactive language training strategy. In broad sense, foreign language learning resources should include two aspects of content, media resources and human resources.

Medium resources involve many aspects, for example, in multimedia and network information 
environment there are a lot of learning resources which can create an almost real language environment, can provide instant messaging from multiple perspectives, and even the international network session. This can largely enhance the foreign language listening and speaking skills, and achieve effective training. Therefore, the network platform construction of foreign language teaching must be accelerated to improve, the digital teaching content should be realized, and the digital education environment which can be used momentarily, and integrates all the teaching and learning resources to meet the needs of students in different levels.

Human resources which can be used in the classroom, including teachers, students, foreign language learners, and international students and so on, are limited. Therefore, improving the students' foreign language application ability can't just rely on the classroom. Teachers should actively organize and lead the students to build the diversity of the second classroom, in order to effectively use the surrounding human resources to achieve the interactive training and learning in-class and after-class. Teachers can timely adopt heuristic and discussion-based teaching method to stimulate students' learning interest. Students' interests and hobbies should be used to promote learning and applying the professional knowledge. This can make the students learn, practice and enjoy it.

\section{Summary}

Network information technology application in foreign language classroom teaching is based on computer technology as the core. And communication platform between teachers and students, students and students could be built by use of voice, text and the show of figure information. So that the visualization of the classroom teaching can create the best language learning environment to improve the students' classroom participation, increase the language practice opportunities, so as to achieve the best teaching effect.

\section{Acknowledgments}

This work was supported by Harbin University of Science and Technology Education Teaching Research Projects (201200046).

\section{References}

[1] A. Martinich: The philosophy of Language (Oxford University Press, New York 2001).

[2] Y. Li: Science and education innovation Vol. 6 (2010), p. 32

[3] T. Kawakita: Takada Junior College Vol. 3 (2013), p. 165-171

[4] Y. K. Cui: The people's education Vol. 6 (2001), p. 46-47

[5] I. Tudor: ELT Journal, Vol. 1 (1993), p. 22-31 